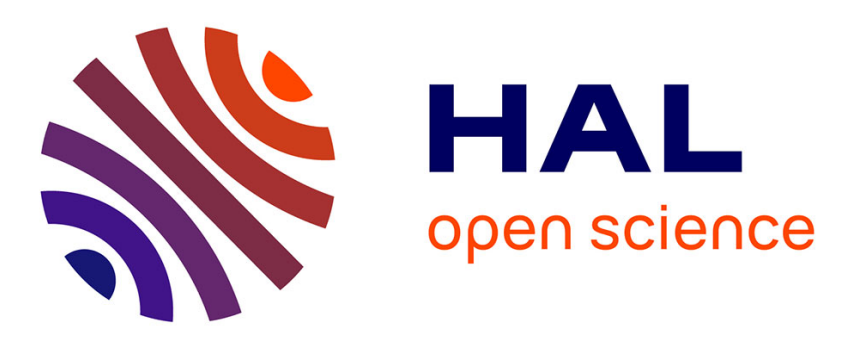

\title{
Optimal Carbon Capture and Storage policies
}

\author{
Alain Ayong Le Kama, Mouez Fodha, Gilles Lafforgue
}

\section{To cite this version:}

Alain Ayong Le Kama, Mouez Fodha, Gilles Lafforgue. Optimal Carbon Capture and Storage policies. Environmental Modelling and Assessment, 2013, 18, pp.417-426. 10.1007/s10666-012-9354-y . insu01103275

\section{HAL Id: insu-01103275 \\ https://hal-insu.archives-ouvertes.fr/insu-01103275}

Submitted on 8 Dec 2019

HAL is a multi-disciplinary open access archive for the deposit and dissemination of scientific research documents, whether they are published or not. The documents may come from teaching and research institutions in France or abroad, or from public or private research centers.
L'archive ouverte pluridisciplinaire HAL, est destinée au dépôt et à la diffusion de documents scientifiques de niveau recherche, publiés ou non, émanant des établissements d'enseignement et de recherche français ou étrangers, des laboratoires publics ou privés. 


\title{
Optimal Carbon Capture and Storage policies
}

\author{
Alain Ayong Le Kama, Mouez Fodha ${ }^{\dagger}$ \\ and Gilles Lafforgue
}

October 2, 2009

\begin{abstract}
Following the IPCC's report (2005), which recommended the development and the use of carbon capture and sequestration (CCS) technologies in order to achieve the environmental goals, defined by the Kyoto Protocol, the issue addressed in this paper concerns the optimal strategy regarding the long-term use of CCS technologies.

The aim of this paper is to study the optimal carbon capture and sequestration policy. The CCS technologies has motivated a number of empirical studies, via complex integrated assessment models. This literature always considers that the existing technology allows sequestrating a fraction of the carbon emissions and concludes that the early introduction of sequestration can lead to a substantial decrease in the cost of environmental externality. But, the level of complexity of such operational models, aimed at defining some specific climate policies.

We develop a very simple growth model so as to obtain analytical and tractable results and therefore exhibit the main driving forces that should determine the optimal CSS policy. We show within this stylized framework that, under some conditions on the cost of extractions, CSS may be a long-term solution for the carbon emissions problem. Besides, it is also shown that the social planner will optimally choose to decrease the rate of capture and sequestration. Besides, we also introduce the decentralization of this simple economy, by considering the individual program of the fossil resource-holder and the one of the representative consumer. This helps us to compute analytically the optimal environmental policy, that is the optimal tax scheme, and also the optimal fossil fuel price profile.
\end{abstract}

\footnotetext{
*Equippe, Université de Lille 1. Email: adayong@univ-paris1.fr

${ }^{\dagger}$ Centre d'Economie de la Sorbonne, University de Paris 1 Panthéon-Sorbonne, CNRS. Email: fodha@univ-paris1.fr

${ }^{\ddagger}$ Toulouse School of Economics (INRA-LERNA). Email: glafforg@toulouse.inra.fr
} 


\section{Introduction}

The IPCC's report (2005) have recommended the development and the use of carbon capture and sequestration (CSS) technologies in order to achieve the environmental goals, defined by the Kyoto Protocol.

Carbon capture and sequestration ${ }^{1}$ is a theoretical approach to mitigating the contribution of fossil fuel emissions to global warming, based on capturing carbon dioxide (CO2) from large point sources such as fossil fuel power plants. The carbon dioxide might then be permanently stored away from the atmosphere. Although $\mathrm{CO} 2$ can be injected into geological formations for various purposes, the long term storage of $\mathrm{CO} 2$ is a relatively untried concept. The first integrated pilot-scale CCS power plant was to begin operating in September 2008 in the eastern German power plant Schwarze Pumpe run by utility Vattenfall, in the hope of answering questions about technological feasibility and economic efficiency. It has been theorized that CCS applied to a modern conventional power plant could reduce $\mathrm{CO} 2$ emissions to the atmosphere by approximately $80-90 \%$ compared to a plant without CCS. The IPCC estimates that the economic potential of CCS could be between $10 \%$ and $55 \%$ of the total carbon mitigation effort until year 2100 (IPCC, 2005).

The issue addressed in this paper concerns the optimal strategy regarding the long-term use of carbon capture and sequestration technologies. Carbon capture and sequestration is a geoengineering technique for the long-term storage of carbon dioxide or other forms of carbon. Carbon dioxide is usually captured from the atmosphere through biological, chemical or physical processes. CO2 may be captured as a pure by-product in processes related to petroleum refining or from flue gases from power generation. CCS usually refers to the large-scale, permanent artificial capture and sequestration of industrially-produced CO2 using subsurface saline aquifers, reservoirs, ocean water, aging oil fields, or other carbon sinks.

Various forms have been conceived for permanent storage of $\mathrm{CO} 2$. These forms include gaseous storage in various deep geological formations (including saline formations and exhausted gas fields), liquid storage in the ocean, and solid storage by reaction of CO2 with metal oxides to produce stable carbonates.

Geological sequestration involves injecting carbon dioxide directly into underground

\footnotetext{
${ }^{1}$ It is more conventional to use the term carbon capture and storage to describe non-biological processes of capturing carbon dioxide from combustion at the source.
} 
geological formations. Oil fields, gas fields, saline formations, and saline-filled basalt formations have been suggested as storage sites. Various physical and geochemical trapping mechanisms would prevent the $\mathrm{CO} 2$ from escaping to the surface. $\mathrm{CO} 2$ is sometimes injected into declining oil fields to increase oil recovery. Approximately 30 to 50 million metric tonnes of $\mathrm{CO} 2$ are injected annually in the United States into declining oil fields. This option is attractive because the geology of hydrocarbon reservoirs are generally well understood and storage costs may be partly offset by the sale of additional oil that is recovered. Disadvantages of old oil fields are their geographic distribution and their limited capacity, as well as that the subsequent burning of the additional oil so recovered will offset much or all of the reduction in $\mathrm{CO} 2$ emissions. For well-selected, designed and managed geological storage sites, the IPCC estimates that $\mathrm{CO} 2$ could be trapped for millions of years, and the sites are likely to retain over $99 \%$ of the injected CO2 over 1,000 years. In 2009 it was reported that scientists had mapped 6,000 square miles of rock formations in the U.S. that could be used to store 500 years worth of U.S. carbon dioxide emissions.

Another proposed form of carbon storage is in the oceans. Several concepts have been proposed:

- dissolution injects CO2 by ship or pipeline into the water column at depths of 1000 $\mathrm{m}$ or more, and the $\mathrm{CO} 2$ subsequently dissolves;

- lake deposits CO2 directly onto the sea floor at depths greater than $3000 \mathrm{~m}$, where CO2 is denser than water and is expected to form a lake that would delay dissolution of $\mathrm{CO} 2$ into the environment.

- convert the CO2 to bicarbonates (using limestone).

Despite the lack of certainty about the long-term economic efficiency of the CSS, many countries have already launched some experiences, which are still operatives. For instance, four important industrial-scale storage projects are in operation:

1- Sleipner is the oldest project (1996) and is located in the North Sea where Norway's StatoilHydro strips carbon dioxide from natural gas with amine solvents and disposes of this carbon dioxide in a deep saline aquifer. The carbon dioxide is a waste product of the field's natural gas production and the gas contains more $(9 \% \mathrm{CO} 2)$ than is allowed into the natural gas distribution network. Storing it underground avoids this problem and saves Statoil hundreds of millions of euro in avoided carbon taxes. Since 1996, Sleipner has stored about one million tonnes CO2 a year. A second project in the Snøhvit gas field in the Barents Sea stores 700,000 tonnes per year. 
2- The Weyburn-Midale CO2 Project is currently the world's largest carbon capture and sequestration project. Started in 2000, Weyburn is located on an oil reservoir discovered in 1954 in Weyburn, southeastern Saskatchewan, Canada. The CO2 for this project is captured at the Dakota Gasification Company plant in Beulah, North Dakota which has produced methane from coal for more than 30 years. At Weyburn, the CO2 will also be used for enhanced oil recovery with an injection rate of about 1.5 million tonnes per year. The first phase finished in 2004, and demonstrated that CO2 can be stored underground at the site safely and indefinitely. The second phase, expected to last until 2009, is investigating how the technology can be expanded on a larger scale.

3- The site of In Salah, which like Sleipner and Snøhvit is a natural gas reservoir located in In Salah, Algeria. The CO2 will be separated from the natural gas and re-injected into the subsurface at a rate of about 1.2 million tonnes per year.

4- In July 2008, the Government of Alberta announced a $\$ 2$ billion investment in three to five large-scale carbon capture and sequestration projects. On June 30, 2009, Government announced three projects it will pursue letters of intent with and work to have the letters signed in the fall. If discussions with these proponents are not successful, Government will evaluate its options and may proceed to discussions with other proponents.

The aim of this paper is to study the optimal carbon capture and sequestration policy. We hence analyze what should be the CSS policy in a deterministic world. ${ }^{2}$ The CSS technologies has motivated a number of empirical studies, via complex integrated assessment models (see McFarland et al. 2003; Edmonds et al. 2004; Kurosawa 2004; Gitz et al. 2005, Edenhofer et al., 2005, Gerlagh, 2006, Gerlagh and van der Zwaan, 2006). These papers consider that the existing technology allows sequestrating a fraction of the carbon emissions. They generally conclude that the early introduction of sequestration can lead to a substantial decrease in the cost of environmental externality. The level of complexity of such operational models, aimed at defining some specific climate policy, may be required so as to take into account the various interactions at hand. In this paper, we consider a stylized model so as to exhibit the main driving forces that should determine the optimal CSS policy, in a very simple economy. While a generic abatement option can take several forms, such as sequestration by forests or pollution reduction at the source, in this paper

\footnotetext{
${ }^{2}$ One direct extension, among others, is to take into account the uncertainty linked to CSS efficiency. The CSS in action are still recent and we do not know exactly the full consequences of such abatement technologies, in terms of environmental consequences (on oceans for instance), or in terms of efficiency once we consider the leakage problems.
} 
we are mainly concerned with the rate of carbon capture and sequestration, although we also introduce the limited size and an access cost of the reservoir. Thus, and by contrast to these previous models, we do not consider the optimal level of carbon emissions to capture and store to achieve a given goal, but we come out with an analytical value of the instantaneous rate of capture and sequestration, that is the optimal rate of storage.

Following Hotteling (1931), Dasgupta and Heal (1974) and Hartwick (1977) who analyze the optimal use (exploitation/depletion) of environmental resources ${ }^{3}$, we consider an optimal growth path of an economy facing a dilemma of consumption vs. pollution. The framework introduced in this paper, the Ramsey model, is quite similar to the one uses in the papers dealing with optimal pollution control (van der Ploeg and Withagen; 1991, Gradus and Smulders; 1996, Ayong Le Kama; 2001, Ayong Le Kama and Schubert; 2004, 2006). Lafforgue et alii. (2008, 2009) and Ragot and Schubert (2009) have already studied the theoretical consequences of the CCS for some specific cases. Lafforgue et alii. (2008, 2009) consider the energy substitution issues when the economy faces a ceiling on the stock of pollution in the atmosphere. Ragot and Schubert (2009) analyze the temporality of sequestration in agricultural soils by considering the asymmetric dynamic process. Finally, Grimaud et alii. study the implications of the CCS technology availability on the optimal use of polluting exhaustible resources and on optimal climate policies, within an endogenous growth framework. They conclude that CSS is detrimental to output growth. But these papers do not consider the CSS technology as a particular tool for the environmental policy. Moreover, in these papers, the rate of change of the stock of pollution or of the stock of the environmental resource, that is the natural rate of absorption/regeneration, is given. The framework introduced here is different since we determine endogenously the optimal rate of carbon sequestration, as if the rate of change of the stock of pollution becomes endogenous. This framework originates from Ayong Le Kama and Fodha (2009) who study the optimal rate of nuclear waste storage, but in a partial equilibrium case. The model introduced in this paper is very simple. We consider an economy with only one good which is fossil energy fuel. This good comes from the extraction of a non-renewable and given resource stock. Its consumption generates environmental damages due to the release of carbon flows into the atmosphere. For simplification, we assume that the flows of carbon are proportional to the level of consumption. Consumption and pollution enter in a separable way into the utility function. Besides, we assume that the social planner

\footnotetext{
${ }^{3}$ See for example Heal (1993) for a survey on these topics.
} 
can capture and store a part of the carbon flow in some appropriately deep sinks. Hence, the social planner goal is to choose the optimal CSS rate policy. We show, under some conditions on the cost of extractions, that CSS may be a long-term solution for the carbon emissions problem. We also introduce a decentralized economy by considering the individual program of the fossil resource-holder and the one of the representative consumer. This will help us to compute analytically the optimal environmental policy, that is the optimal tax scheme, and also the optimal fossil fuel price profile.

The paper is organized as follows. Section 2 describes the model. Section 3 studies the optimal dynamics of fossil resource extraction and sequestration. It also provides an illustration of optimal trajectories by using some specified functional forms. Section 4 derives the decentralized equilibrium outcome and characterizes the carbon tax trajectory that implements the optimum. Finally, section 5 concludes.

\section{The model}

Let us consider an economy in which, at each date $t$, the unique consumption good is a flow of fossil energy fuel $x_{t}$. This good exhibits two main properties. First, it comes from the extraction of a non-renewable and initially given resource stock $X_{0}$. The current fossil resource stock $X_{t}$ thus evolves over time as follows:

$$
\dot{X}_{t}=-x_{t}
$$

We denote by $c\left(X_{t}\right)$ the marginal cost of extraction (also equal to the average cost), which is assumed to be decreasing and convex in $X_{t}$. The marginal extraction cost thus grows as the resource is depleted in order to reflect the fact that the more accessible deposits are exploited first.

Second, consumption of this fossil resource provides utility but it also generates some environmental damages due to the release of carbon flows into the atmosphere associated to the combustion of the fossil fuel. For the sake of simplicity, we assume additive separability between utility and damage (i.e marginal utility is not impacted by pollution). We denote by $u\left(x_{t}\right)$ the instantaneous flow of utility provided by the consumption of $x_{t}$ units of fossil energy and by $v\left(P_{t}\right)$ the instantaneous flow of damage associated with the atmospheric carbon stock $P_{t}$. We assume that $u($.$) has the standard properties (increasing, concave,$ Inada) and that function $v($.$) is increasing and convex. Net utility flows are discounted at$ rate $\rho$, where $\rho$ is the pure rate of time preferences. 
The unitary carbon content of fossil fuel is $\beta$ so that, without any abatement at the pollution source, the instantaneous carbon emissions would be $\beta x_{t}$. We assume that a CCS device is available from the initial date and we note $\gamma_{t}$ the rate of sequestration, i.e. the proportion of carbon emissions that is captured and stored into geological reservoirs. The instantaneous flow of carbon sequestration is then equal to $s_{t}=\gamma_{t} \beta x_{t}$ and the dynamics of storage is given by:

$$
\dot{S}_{t}=s_{t}=\gamma_{t} \beta x_{t}
$$

where $S_{t}$ is the cumulated quantity of carbon stored into carbon sinks, $S_{0}$ been given. We also assume that the maximum amount of $\mathrm{CO}_{2}$ that can be captured and stored is limited by the physical capacity $\bar{S}$ :

$$
S_{t} \leq \bar{S} \quad \forall t
$$

To motivate this assumption, we can argue that carbon emissions are mainly stockpiled into empty geological deposits, such as oil sinks or gas fields, and those potential reservoirs are available themselves in finite quantities. CCS is costly and we assume that the sequestration cost $D\left(\gamma_{t}, x_{t}\right)$ depends both on the level of emissions and the rate of sequestration. ${ }^{4}$ For simplicity, we impose $D\left(\gamma_{t}, x_{t}\right)=\beta x_{t} d\left(\gamma_{t}\right)$, where function $d($.$) is increasing and con-$ vex in $\gamma_{t}$. Then, sequestration costs are linear in carbon emissions, but not in the rate of sequestration in order to reflect decreasing returns in the associated CCS technology.

Finally the atmospheric carbon accumulation process is captured by the following dynamic constraint:

$$
\dot{P}_{t}=\left(1-\gamma_{t}\right) \beta x_{t}-\alpha P_{t}, \quad P_{0} \text { given }
$$

where $\left(1-\gamma_{t}\right) \beta x_{t}$ are the carbon emissions net of abatement and $\alpha$ is the natural rate of decay of the atmosphere.

\section{The optimal extraction and CCS paths}

\subsection{Optimal program and first-order conditions}

Let us denote by $W_{t}$ the objective function, i.e. the social welfare function, of the optimal program:

$$
W_{t}=W\left(X_{t}, S_{t}, P_{t}\right)=\max _{\left\{x_{s}, \gamma_{s}\right\}_{s \geq t}} \int_{t}^{\infty}\left[u\left(x_{s}\right)-v\left(P_{s}\right)-c\left(X_{s}\right) x_{s}-\beta x_{s} d\left(\gamma_{s}\right)\right] e^{-\rho s} d s
$$

\footnotetext{
${ }^{4}$ For the sake of computational conveniences, we do not assume here that the sequestration cost depends on the cumulated past storage $S_{t}$.
} 
Then, we explicitly assume that utility flows are expressed in monetary terms. The social planner chooses a fossil fuel consumption profile $\left(x_{t}\right)_{t \geq 0}$ and a sequestration rate trajectory $\left(\gamma_{t}\right)_{t \geq 0}$ that maximize the social welfare function $W_{t}$ at time $t=0$, subject to constraints (1)-(4) and to:

$$
\begin{aligned}
& x_{t} \geq 0 \\
& 0 \leq \gamma_{t} \leq 1
\end{aligned}
$$

Here we make several points before solving this optimal program. As usually assumed, we will not consider the non-negativity constraints on the state variables. From the Inada condition, the non-negativity constraint on $x_{t}$ will never be binding, except asymptotically, so we do not consider them further here. Finally, we examine the case where the economy is not constrained by (7) and we will check this condition ex-post.

The corresponding Hamiltonian in current value writes:

$$
\begin{aligned}
H= & u\left(x_{t}\right)-v\left(P_{t}\right)-c\left(X_{t}\right) x_{t}-\beta x_{t} d\left(\gamma_{t}\right) \\
& -\lambda_{t} x_{t}+\mu_{t} \gamma_{t} \beta x_{t}+\eta_{t}\left[\left(1-\gamma_{t}\right) \beta x_{t}-\alpha P_{t}\right]+\xi_{t}\left(\bar{S}-S_{t}\right)
\end{aligned}
$$

where $\lambda_{t}, \mu_{t}, \eta_{t}$ are the co-state variables associated with state equations (1), (2) and (4). Those variables read respectively as the scarcity rent of the fossil resource $\left(\partial W_{t} / \partial X_{t}\right)$, the implicit (social) marginal value of carbon capture and storage $\left(\partial W_{t} / \partial S_{t}\right)$, the implicit (social) marginal cost of releasing $\mathrm{CO}_{2}$ into the atmosphere $\left(\partial W_{t} / \partial P_{t}\right)$. Intuitively, along any optimal path, we may obtain non-negative values for $\lambda_{t}$ and non-positive values for $\mu_{t}$ and $\eta_{t}$. Moreover, $\xi_{t}$ denotes the social cost of sequestration coming from a tightening in the limited capacity constraint of reservoir, formally the Lagrange multiplier associated with constraint (3).

The first-order conditions are:

$$
\begin{aligned}
& \frac{\partial H}{\partial x_{t}}=0 \Rightarrow u^{\prime}\left(x_{t}\right)=c\left(X_{t}\right)+\lambda_{t}+\beta\left[d\left(\gamma_{t}\right)-\gamma_{t} \mu_{t}\right]-\left(1-\gamma_{t}\right) \beta \eta_{t} \\
& \frac{\partial H}{\partial \gamma_{t}}=0 \Rightarrow d^{\prime}\left(\gamma_{t}\right)-\mu_{t}=-\eta_{t} \\
& \frac{\partial H}{\partial X_{t}}=\rho \lambda_{t}-\dot{\lambda}_{t} \Rightarrow \dot{\lambda}_{t}=\rho \lambda_{t}+x_{t} c^{\prime}\left(X_{t}\right) \\
& \frac{\partial H}{\partial S_{t}}=\rho \mu_{t}-\dot{\mu}_{t} \Rightarrow \dot{\mu}_{t}=\rho \mu_{t}+\xi_{t} \\
& \frac{\partial H}{\partial P_{t}}=\rho \eta_{t}-\dot{\eta}_{t} \Rightarrow \dot{\eta}_{t}=(\rho+\alpha) \eta_{t}+v^{\prime}\left(P_{t}\right)
\end{aligned}
$$


The complementary slackness condition and the transversality conditions are:

$$
\begin{aligned}
\xi_{t}\left(\bar{S}-S_{t}\right) & =0, \quad \xi_{t} \geq 0 \\
\lim _{t \rightarrow \infty} \lambda_{t} X_{t} e^{-\rho t} & =0 \\
\lim _{t \rightarrow \infty} \mu_{t} S_{t} e^{-\rho t} & =0 \\
\lim _{t \rightarrow \infty} \eta_{t} P_{t} e^{-\rho t} & =0
\end{aligned}
$$

Equation (8) equates the marginal utility of consuming one unit of fossil energy with its full marginal cost. This last term can be decomposed in: i) the marginal extraction cost $c\left(X_{t}\right)$, ii) the resource scarcity rent $\lambda_{t}$, iii) the full cost of sequestration $\beta\left[d\left(\gamma_{t}\right)-\gamma_{t} \mu_{t}\right]$ by unit of fossil fuel use, and iv) the marginal social cost of augmenting the atmospheric carbon stock by the flow of residual emissions, i.e. $\left(1-\gamma_{t}\right) \beta \eta_{t}$. Equation (9) says that the full marginal cost of carbon burying (left-hand-side) must be equal to its social marginal gain in terms of atmospheric carbon concentration reduction (right-hand side). Equation (10) is no other than the Hotelling rule in the case of stock-dependent extraction costs. Equation (11) implies that the implicit marginal value of CCS must grow at the pure rate of time preferences $\rho$, augmented by $\xi_{t}$ which reflects the limited capacity of carbon sinks. Note that, from (13), this last term is nil as long as the reservoir is not fulfilled and non-negative otherwise, which means that $\mu_{t}$ obeys to the Hotelling rule only during the phase along which CCS is active. Finally, equation (12) says that the social marginal cost of atmospheric $\mathrm{CO}_{2}$ accumulation must grows at a rate equal to the sum of the pure rate of time preferences augmented by the natural rate of decay ${ }^{5}$, and the marginal damage.

Finally, remark that replacing $(\mu-\eta)$ by $d^{\prime}(\gamma)$ from (9), the first-order condition (8) can be rewritten as:

$$
u^{\prime}\left(x_{t}\right)=c\left(X_{t}\right)+\lambda_{t}+\beta\left[d\left(\gamma_{t}\right)-\gamma_{t} d^{\prime}\left(\gamma_{t}\right)-\eta_{t}\right]
$$

\subsection{Optimal dynamics}

First, we solve the non-homogeneous differential equations (11) and (12) by using the associated transversality conditions (15) and (16), respectively, in order to identify initial values

\footnotetext{
${ }^{5}$ This first term can be seen as a "modified" discount rate in order to take into account that emitting an additional unit of carbon today yields a marginal return $\rho$ tomorrow, but it also increases the future marginal regeneration of the atmosphere by $\alpha$.
} 
$\mu_{0}$ and $\eta_{0}$. For any $t$, solutions are given by (stars in exponent refer here to optimality):

$$
\begin{aligned}
\mu_{t}^{*} & =-\int_{t}^{\infty} \xi_{s} e^{-\rho(s-t)} d s \\
\eta_{t}^{*} & =-\int_{t}^{\infty} v^{\prime}\left(P_{s}\right) e^{-(\rho+\alpha)(s-t)} d s
\end{aligned}
$$

Since $\xi_{t} \geq 0$ from (13) and $v^{\prime}()>$.0 by assumption, we can then check that $\mu_{t}^{*}$ and $\eta_{t}^{*}$ are non-positive for any $t$. The social marginal cost of sequestration (by unit of $\mathrm{CO}_{2}$ emitted) is equal to the discounted sum over time of the instantaneous costs of the reservoir capacity constraint, from $t$ up to $\infty$. The social marginal cost of atmospheric carbon concentration is equal to the discounted sum (at rate $\rho+\alpha$ ) over time of instantaneous marginal damages, from $t$ up to $\infty$.

Next, to solve the optimal program in the deterministic case without leakage, we need to find the optimal expression of $\xi_{t}$. Let us assume that the carbon reservoir is fulfilled at a finite date $\bar{t}<<\infty$. We will discuss about an eventual asymptotic fulfilling up of the reservoir later. Obviously, $\bar{t}$ is determined from $S_{\bar{t}}=\bar{S}$ and thus depends on the size $\bar{S}$ of the reservoir. For any date $t>\bar{t}$, we have $\dot{S}_{t}=0$, which implies $\gamma_{t} \beta x_{t}=0$. But due to the Inada conditions that we have imposed, the fossil resource stock can be exhausted only asymptotically, which finally implies $\gamma_{t}=0$ for any $t \geq \bar{t}$. Since, in that case, (9) writes $d^{\prime}(0)=\mu_{t}-\eta_{t}$, we must have $\dot{\mu}_{t}-\dot{\eta}_{t}=0, \forall t>\bar{t}$. From (11) and (12), we thus obtain $\xi_{t}=\alpha \eta_{t}+v^{\prime}\left(P_{t}\right)-\rho d^{\prime}(0), \forall t \geq \bar{t}$, which, by using (19), implies:

$$
\xi_{t}^{*}= \begin{cases}0 & , t<\bar{t} \\ v^{\prime}\left(P_{t}\right)-\rho d^{\prime}(0)-\alpha \int_{t}^{\infty} v^{\prime}\left(P_{s}\right) e^{-(\rho+\alpha)(s-t)} d s & , t \geq \bar{t}\end{cases}
$$

Recall that $\xi_{t}^{*}$ reads as the optimal social value of the limited capacity constraint of carbon reservoirs or, in other words, as the marginal increase of social welfare coming from a marginal increase of $\bar{S}$. It is equal to zero as long as the reservoir is not filled, and it takes some positive value thereafter. Moreover, from the non-negativity condition (13), we must impose the following constraint:

$$
\frac{1}{\rho}\left[v^{\prime}\left(P_{t}\right)-\alpha \int_{t}^{\infty} v^{\prime}\left(P_{s}\right) e^{-(\rho+\alpha)(s-t)} d s\right]>d^{\prime}(0), \quad \forall t>\bar{t}
$$

which states that it is optimal to fulfill up the carbon sink in finite time if and only if the net marginal damage divided by the social discount rate at some future date after fulfilling is larger than the initial marginal sequestration cost by unit of $\mathrm{CO}_{2}$ emission. Here, the net marginal damage at date $t$ is defined by the instantaneous marginal damage $v^{\prime}\left(P_{t}\right)$ at 
this date, diminished by the discounted sum (at rate $\rho+\alpha$ ) from $t$ up to infinity of all the marginal damages that will be avoided owing to natural cleaning-up of the atmosphere.

Replacing $\xi_{t}^{*}$ by its expression (20) into (18), expanding computations and after simplifications, we obtain:

$$
\mu_{t}^{*}= \begin{cases}-\int_{\bar{t}}^{\infty} v^{\prime}\left(P_{s}\right) e^{-\rho(s-t)} e^{-\alpha(s-\bar{t})} d s+d^{\prime}(0) e^{-\rho(\bar{t}-t)} & , t<\bar{t} \\ -\int_{t}^{\infty} v^{\prime}\left(P_{s}\right) e^{-(\rho+\alpha)(s-t)} d s+d^{\prime}(0) & , t \geq \bar{t}\end{cases}
$$

We determine now the optimal dynamics of the two control variables $x_{t}$ and $\gamma_{t}$. We start with $\gamma_{t}$ by differentiating (9) with respect to time and by replacing $\dot{\mu}_{t}$ and $\dot{\eta}_{t}$ by their expressions coming from (11) and (12), respectively:

$$
d^{\prime \prime}\left(\gamma_{t}\right) \dot{\gamma}_{t}=\rho \mu_{t}+\xi_{t}-(\rho+\alpha) \eta_{t}-v^{\prime}\left(P_{t}\right)
$$

Using (9) again, it comes:

$$
d^{\prime \prime}\left(\gamma_{t}\right) \dot{\gamma}_{t}=\rho d^{\prime}\left(\gamma_{t}\right)+\xi_{t}-\alpha \eta_{t}-v^{\prime}\left(P_{t}\right)
$$

Proceeding in the same way with $x_{t}$ (i.e. differentiating (17) with respect to time and replacing the time derivatives of the co-state variables by their corresponding expressions), we obtain after simplifications:

$$
u^{\prime \prime}\left(x_{t}\right) \dot{x}_{t}=\rho\left(\lambda_{t}-\beta \eta_{t}\right)-\beta \gamma_{t} d^{\prime \prime}\left(\gamma_{t}\right) \dot{\gamma}_{t}-\beta\left[\alpha \eta_{t}+v^{\prime}\left(P_{t}\right)\right]
$$

which, once have been used (24), becomes:

$$
u^{\prime \prime}\left(x_{t}\right) \dot{x}_{t}=\rho\left[\lambda_{t}-\beta \eta_{t}-\beta \gamma_{t} d^{\prime}\left(\gamma_{t}\right)\right]-\beta\left\{\gamma_{t} \xi_{t}+\left(1-\gamma_{t}\right)\left[\alpha \eta_{t}+v^{\prime}\left(P_{t}\right)\right]\right\}
$$

Using (17) again and replacing $\xi_{t}$ by its expression coming from (24), we finally get:

$$
u^{\prime \prime}\left(x_{t}\right) \dot{x}_{t}=\rho\left[u^{\prime}\left(x_{t}\right)-c\left(X_{t}\right)-\beta d\left(\gamma_{t}\right)+\beta \gamma_{t} d^{\prime}\left(\gamma_{t}\right)\right]-\beta\left[\gamma_{t} d^{\prime \prime}\left(\gamma_{t}\right) \dot{\gamma}_{t}+\alpha \eta_{t}+v^{\prime}\left(P_{t}\right)\right]
$$

where $\eta_{t}$ is defined by (19). Unfortunately, without specifying functional forms, we are not able to go further in the computation of the optimal trajectories. In the next subsection, we provide an analytical example of optimal sequestration and consumption trajectories. 


\subsection{Analytical example}

We first postulate that the marginal damage is constant over time: $v^{\prime}\left(P_{t}\right)=v, \forall t \geq 0$. With this analytical simplification, expressions (19), (20) and (22) become:

$$
\begin{aligned}
& \eta_{t}^{*}=\frac{-v}{\rho+\alpha} \\
& \xi_{t}^{*}= \begin{cases}0 & , t<\bar{t} \\
\rho\left[\frac{v}{\rho+\alpha}-d^{\prime}(0)\right], & , t \geq \bar{t}\end{cases} \\
& \mu_{t}^{*}= \begin{cases}-\left[\frac{v}{\rho+\alpha}-d^{\prime}(0)\right] e^{-\rho(\bar{t}-t)} & , t<\bar{t} \\
-\left[\frac{v}{\rho+\alpha}-d^{\prime}(0)\right] & , t \geq \bar{t}\end{cases}
\end{aligned}
$$

Assuming a constant marginal damage leads to constant implicit costs of reservoir limited capacity constraint $\xi^{*}$ and atmospheric $\mathrm{CO}_{2}$ concentrations $\eta^{*}$. This last result implies that the net present value of future damages, discounted at rate $(\rho+\alpha)$ is constant over time. Moreover, the implicit cost of CCS $\mu_{t}^{*}$ becomes constant at the date at which the carbon reservoir is filled. Beforehand, it is increasing over time and continuity condition at $t=\bar{t}$ is satisfied. Remark that the existence condition (21) writes now:

$$
\frac{v}{\rho+\alpha}>d^{\prime}(0)
$$

which implies that the net present value of future damages must be larger than the initial marginal sequestration cost in order to provide incentives enough for CCS.

We have next recourse to the same quadratic CCS cost function than in Gerlagh et al. (2006), and which is defined as follows:

$$
d\left(\gamma_{t}\right)=\gamma_{t}\left(1+\frac{\kappa}{2} \gamma_{t}\right)
$$

where $\kappa, \kappa>0$ is the index of convexity of this function, i.e. $d^{\prime \prime}()=.\kappa$. Remark that the initial marginal sequestration cost by unit of emission is now unitary, i.e. $d^{\prime}(0)=1$. Consequently, the existence condition (21) is reduced to $v>\rho+\alpha$, i.e. the instantaneous marginal damage must be larger than the "modified" social discount rate. Introducing these specifications into (24) yields to:

$$
\dot{\gamma}_{t}=\rho \gamma_{t}+\frac{1}{\kappa}\left[\xi^{*}-\rho\left(\frac{v}{\rho+\alpha}-1\right)\right]
$$

Given (29) and the fact that $\gamma_{t}=0$ for any $t \geq \bar{t}$ by definition of $\bar{t}$, the solution of the non-homogeneous differential equation (33) is:

$$
\gamma_{t}^{*}= \begin{cases}\frac{1}{\kappa}\left(\frac{v}{\rho+\alpha}-1\right)\left[1-e^{-\rho(\bar{t}-t)}\right] & , t<\bar{t} \\ 0 & , t \geq \bar{t}\end{cases}
$$


where the initial value of $\gamma_{t}^{*}$ is given by:

$$
\gamma_{0}^{*}=\frac{1}{\kappa}\left(\frac{v}{\rho+\alpha}-1\right)\left(1-e^{-\rho \bar{t}}\right)
$$

Let us finally turn to the computation of the optimal energy consumption path. Using the analytical specifications introduced above, (27) reduces to:

$$
u^{\prime \prime}\left(x_{t}\right) \dot{x}_{t}=\rho\left[u^{\prime}\left(x_{t}\right)-c\left(X_{t}\right)-\beta \gamma_{t}\left(1+\frac{\kappa}{2} \gamma_{t}\right)-\beta\left(1-\gamma_{t}\right) \frac{v}{\rho+\alpha}\right]-\beta \gamma_{t} \xi^{*}
$$

which, by using (29), can be expanded as follows:

$$
\dot{x}_{t}= \begin{cases}\frac{\rho}{u^{\prime \prime}\left(x_{t}\right)}\left[u^{\prime}\left(x_{t}\right)-c\left(X_{t}\right)+\left.\beta \gamma_{t}^{*}\right|_{t<\bar{t}}\left(\frac{v}{\rho+\alpha}-1-\left.\frac{\kappa}{2} \gamma_{t}^{*}\right|_{t<\bar{t}}\right)-\frac{\beta v}{\rho+\alpha}\right] & , t<\bar{t} \\ \frac{\rho}{u^{\prime \prime}\left(x_{t}\right)}\left[u^{\prime}\left(x_{t}\right)-c\left(X_{t}\right)-\frac{\beta v}{\rho+\alpha}\right] & , t \geq \bar{t}\end{cases}
$$

where $\left.\gamma_{t}^{*}\right|_{t<\bar{t}}$ is determined from (34). Once $\gamma_{t}$ have been replaced replaced by its optimal expression (34) into (36), we get an autonomous system of non-homogeneous differential equations in $\left(x_{t}, X_{t}\right)_{t \geq 0}$, together with $(1)$, that can be solved. From the determination of optimal controls $\gamma_{t}^{*}$ and $x_{t}^{*}$, we will next be able to characterize $S_{t}^{*}$ and $P_{t}^{*}$. Finally, from the continuity condition on stock $S_{t}$, we will characterize the optimal date $\bar{t}$ of carbon reservoir filling up, depending upon the limited capacity $\bar{S}$ and the other parameters of the model. However, at this step, we need functional forms for $u($.$) and c($.$) to solve the$ problem at the end. We pose $u\left(x_{t}\right)=a \ln x_{t}$ and $c\left(X_{t}\right)=c$, with $a, c>0$.

Eliminating the stock effect on fossil resource extraction significantly simplifies the problem since it make differential equation (10) homogeneous. When the marginal extraction cost is constant, we recover the standard Hotelling rule $\dot{\lambda}_{t}=\rho \lambda_{t}$, whose solution is $\lambda_{t}^{*}=\lambda_{0} e^{\rho t}$, where $\lambda_{0}$ is such that $\int_{0}^{\infty} x_{t}^{*}=X_{0}$. First-order (17) condition can be thus rewritten as:

$$
\frac{a}{x_{t}^{*}}=c+\lambda_{0} e^{\rho t}-\beta\left(\frac{\kappa \gamma_{t}^{* 2}}{2}+\eta_{t}^{*}\right)=c+\frac{\beta v}{\rho+\alpha}+\lambda_{0} e^{\rho t}-\frac{\beta \kappa \gamma_{t}^{* 2}}{2}
$$

Given (34), this expression is equivalent to:

$$
x_{t}^{*}= \begin{cases}a\left[c+\frac{\beta v}{\rho+\alpha}+\lambda_{0} e^{\rho t}-\frac{\beta}{2 \kappa}\left(\frac{v}{\rho+\alpha}-1\right)^{2}\left(1-e^{-\rho(\bar{t}-t)}\right)^{2}\right]^{-1} & , t<\bar{t} \\ a\left[c+\frac{\beta v}{\rho+\alpha}+\lambda_{0} e^{\rho t}\right]^{-1} & , t \geq \bar{t}\end{cases}
$$

and then, the initial energy consumption level is:

$$
x_{0}^{*}=a\left[c+\frac{\beta v}{\rho+\alpha}+\lambda_{0}-\frac{\beta}{2 \kappa}\left(\frac{v}{\rho+\alpha}-1\right)^{2}\left(1-e^{-\rho \bar{t}}\right)^{2}\right]^{-1}
$$


All these findings are summarized into the following proposition.

Proposition 1 In the specific analytical example introduced above, the optimal sequestration rate and the optimal energy consumption $\left\{\gamma_{t}^{*}, x_{t}^{*}\right\}$ are characterized by:

$$
\begin{aligned}
& \gamma_{t}^{*}= \begin{cases}\frac{1}{\kappa}\left(\frac{v}{\rho+\alpha}-1\right)\left[1-e^{-\rho(\bar{t}-t)}\right] & , t<\bar{t} \\
0 & , t \geq \bar{t}\end{cases} \\
& x_{t}^{*}=a\left[c+\frac{\beta v}{\rho+\alpha}+\lambda_{0}^{*} e^{\rho t}-\frac{\beta \kappa \gamma_{t}^{* 2}}{2}\right]^{-1}, t \geq 0
\end{aligned}
$$

where the couple of variables $\left\{\bar{t}, \lambda_{0}^{*}\right\}$ is determined by the following system of equations:

$$
\begin{aligned}
\int_{0}^{\infty} x_{t}^{*} & =X_{0} \\
\beta \int_{0}^{\bar{t}} \gamma_{t}^{*} x_{t}^{*} d t & =\bar{S}
\end{aligned}
$$

Those solutions are illustrated in Figure (1). Since $\dot{\gamma}=-\frac{\rho}{\kappa}\left(\frac{v}{\rho+\alpha}-1\right) e^{-\rho(\bar{t}-t)}<0$, the optimal sequestration rate starts from its initial value $\gamma_{0}^{*}$ as defined by (35), and declines over time up to 0 which is reached at date $\bar{t}$, as showed in the northeast quadrant of Figure (1). The northwest quadrant draws the optimal fossil energy as a function of the optimal sequestration rate. Since from (41), (42) can be rewritten as $x^{*}\left(\gamma_{t}^{*}\right)=$ $a\left[c+\frac{\beta v}{\rho+\alpha}+\lambda_{0}^{*} e^{\rho \bar{t}}-\lambda_{0}^{*} \kappa\left(\frac{\rho+\alpha}{v-\rho-\alpha}\right) \gamma_{t}^{*}-\frac{\beta \kappa}{2} \gamma_{t}^{* 2}\right]^{-1}$ for any $t<\bar{t}$, it is easy to see that this energy consumption function is increasing and convex in $\gamma^{*}$. The southwest quadrant is a purely technical device to show how the energy consumption is derived from the sequestration rate at the same time, which is finally illustrated in the southeast quadrant of Figure (1). We thus obtain an optimal consumption trajectory that is declining over time and continuous at $t=\bar{t}$, but that exhibits a kink at $t=\bar{t}$ (i.e. its slope is discontinuous at this point of time). Note that, for any $t \geq \bar{t}$, the rest of the optimal trajectory is characterized by (42) when $\gamma_{t}^{*}=0$. As expected, the fossil resource exhaustion occurs then asymptotically.

Let us now check the existence conditions of the optimal solutions mentioned in Proposition 1. First, a direct implication of $\xi_{t}^{*} \geq 0$ is that $\gamma_{t}^{*} \geq 0$ for any $t$. Second, a necessary and sufficient condition for having $\gamma_{t}^{*}$ smaller than 1 is $\gamma_{0}^{*} \leq 1$. Such a condition leads to:

$$
\bar{t} \leq-\frac{1}{\rho} \ln \left[1-\frac{\kappa(\rho+\alpha)}{v-\rho-\alpha}\right]
$$




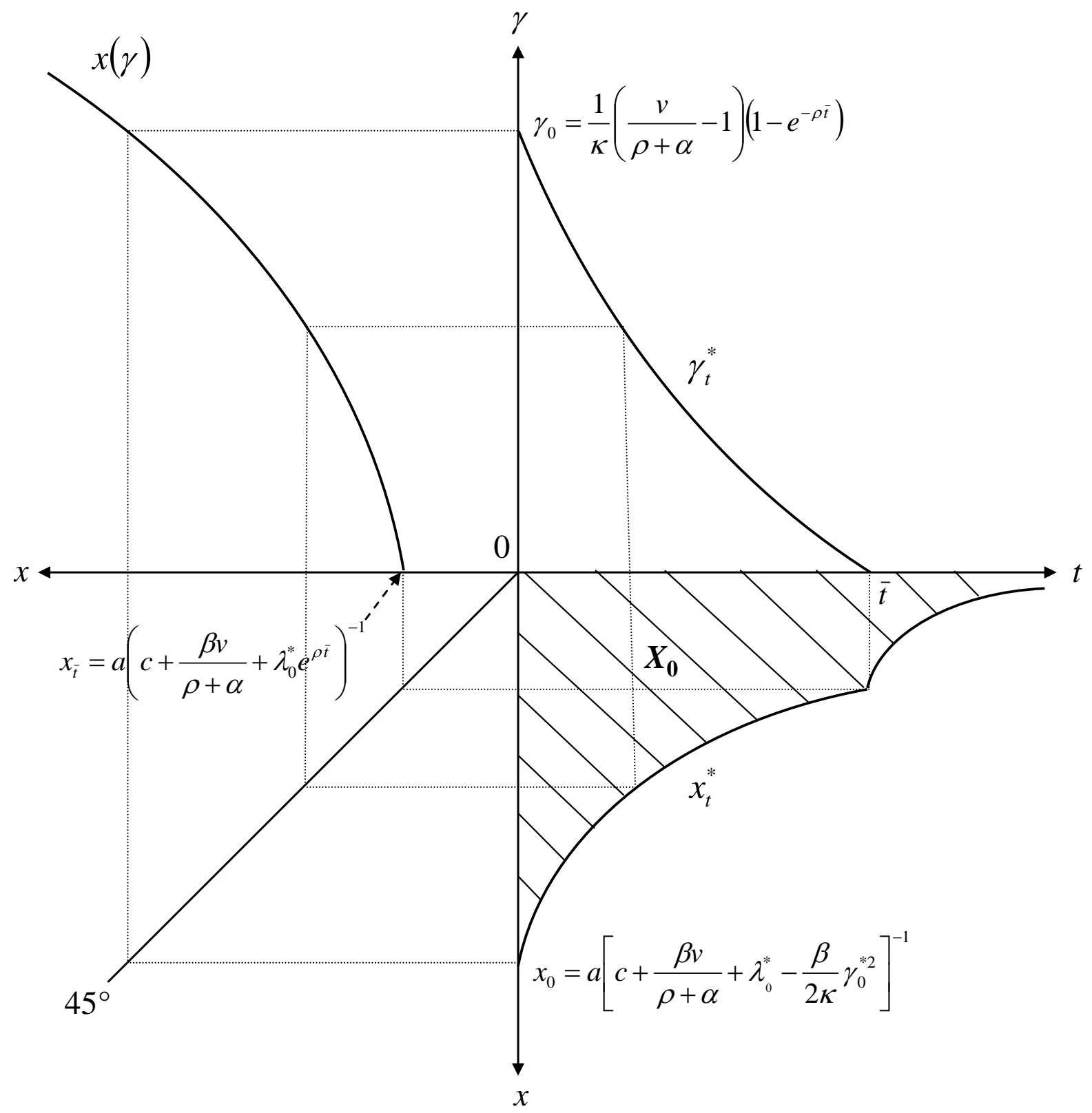

Figure 1: Optimal sequestration rate and fossil energy consumption 
Condition (45) also provides some insights about the value of $\bar{t}$. If $v>(\rho+\alpha)(\kappa+1),(45)$ guarantees that carbon reservoir is fulfilled in finite time. Else, $\bar{t}$ can be finite as well as infinite. Finally, we have $x_{t}^{*} \geq 0$ for any $t \geq \bar{t}$ and $x_{\bar{t}}^{*}>0$, which insures that $x_{t}^{*}>0$ for any $t<\bar{t}$ since $x_{t}^{*}$ is monotonically decreasing over time. The following table summarizes these findings.

\begin{tabular}{c|c|c|c} 
Condition for: & $v \leq \rho+\alpha$ & $\rho+\alpha<v \leq(\kappa+1)(\rho+\alpha)$ & $(\kappa+1)(\rho+\alpha)<v$ \\
\hline$\gamma_{t}^{*}>0$ & No & Yes & Yes \\
$\gamma_{t}^{*} \leq 1$ & Yes & Yes & Yes \\
$\bar{t}$ finite & Not necessary & Not necessary & Yes
\end{tabular}

Table 1: Conditions of existence

\section{Decentralization of the economy and implementation of the optimum}

In this section, we decentralize the economy which have been studied above by considering the individual programs of the fossil resource-holder and of the consumer. We assume perfect competitive markets and we denote by $p_{t}$ and $r_{t}$ the fossil fuel price and the real interest rate on financial markets, respectively. In order to correct the environmental externality, we introduce a carbon tax profile $\left\{\tau_{t}\right\}_{t=0}^{\infty}$. Note that, due to the CCS device, the tax applies on the sole part of carbon emissions which are effectively released into the atmosphere after sequestration. In that sense, carbon taxation is disconnected from the fossil resource use.

The resource-holder chooses the extraction path $\left\{x_{t}\right\}_{t=0}^{\infty}$ that maximizes the discounted sum over time of its current profits $\int_{0}^{\infty}\left[p_{t}-c\left(X_{t}\right)\right] x_{t} \exp \left(-\int_{0}^{t} r_{s} d s\right) d t$ subject to the constraint (1). First-order conditions imply:

$$
\dot{p}_{t}=r_{t}\left[p_{t}-c\left(X_{t}\right)\right]
$$

which is no other than the standard Hotelling rule with extraction costs, and which states that the resource rent must grow at the real interest rate.

The program of the resource-user consists in choosing the consumption and sequestration rate trajectories $\left\{x_{t}\right\}_{t=0}^{\infty}$ and $\left\{\gamma_{t}\right\}_{t=0}^{\infty}$ that maximize $\int_{0}^{\infty}\left[u\left(x_{t}\right)-\beta x_{t} d\left(\gamma_{t}\right)-p_{t} x_{t}-\tau_{t}(1-\right.$ $\left.\left.\gamma_{t}\right) \beta x_{t}\right] \exp (-\rho t) d t$, subject to constraints (2), (3) and (7). As in the previous section, we 
examine the case where the decision-maker is not constrained by (7), which leads to the following first-order conditions:

$$
\begin{aligned}
u^{\prime}\left(x_{t}\right) & =\beta d\left(\gamma_{t}\right)+p_{t}+\tau_{t} \beta\left(1-\gamma_{t}\right)-\beta \gamma_{t} \mu_{t}^{e} \\
d^{\prime}\left(\gamma_{t}\right) & =\tau_{t}+\mu_{t}^{e} \\
\dot{\mu}_{t}^{e} & =\rho \mu_{t}^{e}+\xi_{t}^{e}
\end{aligned}
$$

where, by analogy with the optimal program, $\mu_{t}^{e}$ and $\xi_{t}^{e}$ are, respectively, the multipliers associated with constraints (2) and (3), but now expressed at the equilibrium. Differentiating (47) with respect to time and using (48), it comes:

$$
u^{\prime \prime}\left(x_{t}\right) \dot{x}_{t}=\dot{p}_{t}+\beta \dot{\tau}_{t}-\beta \gamma_{t} d^{\prime \prime}\left(\gamma_{t}\right) \dot{\gamma}_{t}
$$

Along any equilibrium trajectory, $p_{t}$ is governed by the dynamic condition (46) so that, after simplifications and using (47) again, (50) can be rewritten as:

$$
u^{\prime \prime}\left(x_{t}\right) \dot{x}_{t}=r_{t}\left\{u^{\prime}\left(x_{t}\right)-c\left(X_{t}\right)-\beta\left[d\left(\gamma_{t}\right)+\gamma_{t} d^{\prime}\left(\gamma_{t}\right)+\tau_{t}\right]\right\}+\beta \dot{\tau}_{t}-\beta \gamma_{t} d^{\prime \prime}\left(\gamma_{t}\right) \dot{\gamma}_{t}
$$

There exists a particular equilibrium $\left\{x_{t}^{e}\left(\tau_{t}\right), \gamma_{t}^{e}\left(\tau_{t}\right)\right\}$ associated with any carbon tax trajectory. This set of equilibria is characterized by the condition (51) above. By analogy between this condition and the corresponding condition (27), we can determine the carbon tax trajectory that implements the optimum. Noting that the optimal interest rate must be equal to the social time preference index, i.e. $r_{t}^{o}=\rho, \forall t \geq 0$, the optimal tax scheme $\tau_{t}^{o}$ is such that:

$$
\dot{\tau}_{t}^{o}=\rho \tau_{t}^{o}-\alpha \eta_{t}^{*}-v^{\prime}\left(P_{t}^{*}\right)
$$

where $\eta_{t}^{*}$ is defined by (19) and where $P_{t}^{*}$ denotes the trajectory of atmospheric carbon accumulation that is followed at the optimum. Results about the implementation of the optimum are summarized in the following proposition.

Proposition 2 The optimal environmental policy and the associated interest rate and fossil fuel price are given by:

$$
\begin{aligned}
\tau_{t}^{o} & =\tau_{0}^{o} e^{\rho t}-\int_{0}^{t}\left[\alpha \eta_{s}^{*}+v^{\prime}\left(P_{s}^{*}\right)\right] e^{-\rho(s-t)} d s \\
r_{t}^{o} & =\rho \\
p_{t}^{o} & =p_{0}^{o} e^{\rho t}-\rho \int_{0}^{t} c\left(X_{s}^{*}\right) e^{-\rho(s-t)} d s
\end{aligned}
$$


where the initial values of $\tau_{t}^{o}$ and $p_{t}^{o}$ are determined by:

$$
\begin{aligned}
\tau_{0}^{o} & =\frac{1}{\beta}\left[u^{\prime}\left(x_{0}^{*}\right)-\beta d\left(\gamma_{0}^{*}\right)+\beta \gamma_{0}^{*} d^{\prime}\left(\gamma_{0}^{*}\right)-p_{0}^{o}\right] \\
p_{0}^{o} & =c\left(X_{0}\right)+\lambda_{0}^{*}, \quad \text { with } \lambda_{0}^{*} \text { s.t. } \int_{0}^{\infty} x_{t}^{*} d t=X_{0}
\end{aligned}
$$

Finally, we illustrate those findings by using the same analytical forms than the ones that have been introduced in the previous section. Under specifications, we obtain $p_{t}^{o}=$ $c+\lambda_{0}^{*} \exp (\rho t)$ from (55) and (57). From (53), the specified optimal tax trajectory writes $\tau_{t}^{o}=\tau_{0}^{o} \exp (\rho t)+(1-\exp (\rho t)) v /(\rho+\alpha)$. However, from (56), we find an initial level of tax equal to $v /(\rho+\alpha)$. This implies that, in the specified version of the model, the optimal carbon tax is constant over time and equal to $\tau_{t}^{o}=v /(\rho+\alpha), \forall t \geq 0$. The optimal carbon price at any time $t$ should be equal to the sum from $t$ up to $\infty$ of the future marginal damage involved by the emission at time $t$ of one unit of carbon and discounted at rate $(\rho+\alpha)$ in order to take into account that carbon is naturally absorbed into the atmosphere at rate $\alpha$ by unit of time. Obviously, in the special case where instantaneous marginal damages are considered as constant, the optimal carbon tax should also be constant over time.

\section{Conclusion}

Following the IPCC's report (2005), which recommended the development and the use of carbon capture and sequestration (CSS) technologies in order to achieve the environmental goals, defined by the Kyoto Protocol, the issue we have addressed in this paper concerns the optimal strategy regarding the long-term use of carbon capture and sequestration technologies.

The aim of this paper was to study the optimal carbon capture and sequestration policy. We then tried to analyze what should be the CSS optimal policy in a deterministic world. As we pointed out in the introduction, the CCS technologies has motivated a number of empirical studies, via complex integrated assessment models. This literature always considers that the existing technology allows sequestrating a fraction of the carbon emissions and concludes that the early introduction of sequestration can lead to a substantial decrease in the cost of environmental externality. But, the level of complexity of such operational models, aimed at defining some specific climate policies. In this paper, we have introduced a very simple model so as to obtain analytical and tractable results and therefore exhibit the main driving forces that should determine the optimal CSS policy. 
We have shown within this model that, under some conditions on the cost of extractions, CSS may be a long-term solution for the carbon emissions problem. Besides, it is also shown that the social planner will optimally choose to decrease the rate of capture and sequestration. We have also introduced a decentralized economy by considering the individual program of the fossil resource-holder and the one of the representative consumer. This helped us to compute analytically the optimal environmental policy, that is the optimal tax scheme, and also the optimal fossil fuel price profile.

However, all this results are obtained in a deterministic world. One direct and natural extension of the model, among others, might be to take into account the uncertainty linked to CSS efficiency. The CSS technologies in action are still recent and we do not know exactly the full consequences of such abatement technologies, in terms of environmental consequences (on oceans for instance), or in terms of efficiency once we consider the leakage problems.

Introducing a risk of leakage in this model will certainly brings more insights on the understanding and the characterizing of the optimal carbon capture and sequestration policy. One easy way to do that is, like in Ayong Le Kama (2001), to assume for example that there is a possibility that at a random future date, with a given marginal density (with a known distribution, Poisson or Exponential), an accident may occur, with a given probability, which implies a leakage, that is a destocking of a part of the accumulated quantity of carbon stored.

Extending the framework of the paper by introducing this double uncertainty (on the level of the leakage and on the date at which this occurs), which is more close to the real world, will significantly change the behavior of the central planner. For example, under uncertainty, the marginal utility of consuming one unit of fossil energy will now be equal to its expected full marginal cost. Namely, the levels of resource scarcity rent, of the CCS cost and of the marginal social cost of augmenting the atmospheric carbon stock by the flow of residual emissions will all depend on whether or not the accident has occurred. It will be the same for the equality between the full marginal cost of the CCS technology and its net social marginal gain; it will hold only if the accident has never occurred. Besides, the Hotelling rule will be completely modified, the evolution of the scarcity rent will in this case, as it is the case in the real world, on the marginal valuation of the non-renewable resource stock available at each time t. This will also be the case for the growth rate of the social marginal cost of atmospheric $\mathrm{CO} 2$ which will depend not only on the probability that the accident occurs, but also on the expected marginal bequest of pollution, that is 
the marginal negative valuation of the atmospheric pollution stock time $t$.

All these examples point out the fact that it is necessary to take into account the management of the risk of leakage when we want to study the optimal CCS policies. This paper has tried to first exhibit the main driving forces that should determine these optimal policies, but in a deterministic world. The next step is by the way... natural. 


\section{References}

[1] Ayong Le Kama, A., 2001. Preservation and exogenous uncertain future preferences. Economic Theory 18, 745-752.

[2] Ayong Le Kama, A., Fodha, M., 2009. Optimal Nuclear Waste Burial Policy under Uncertainty. CES Working Paper.

[3] Ayong Le Kama, A., Schubert K., 2004. Growth, Environment and Uncertain Future Preferences. Environmental and Resource Economics 28, 31-53.

[4] Ayong Le Kama, A., Schubert, K., 2006. Ressources renouvelables et incertitude sur les préférences des générations futures. Revue d'Economie Politique 2, 229-250.

[5] Dasgupta, P., Heal, G., 1974. The Optimal Depletion of Exhaustible Resources, Review of economic studies 41, 1-28.

[6] Edenhofer, O., Bauer, N., Kriegler, E., 2005. The impact of technological change on climate protection and welfare: insights from the model MIND. Ecol. Econ. 54, $277-292$.

[7] Edmonds, J., Clarke, J., Dooley, J., Kim, S.H., Smith, S.J., 2004. Stabilization of $\mathrm{CO} 2$ in a B2 world: insights on the roles of carbon capture and disposal, hydrogen, and transportation technologies. Energy Economics. 26, 517-537.

[8] Gerlagh, R., 2006. ITC in a global growth-climate model with CCS. The value of induced technical change for climate stabilization. Energy Journal, 1, 55-72 Special issue.

[9] Gerlagh, R., van der Zwaan, B.C., 2006. Options and instruments for a deep Cut in CO2 emissions: carbon capture or renewable, taxes or subsidies? Energy Journal, 27, $25-48$.

[10] Gitz, V., Ambrosi, P., Magné, B., Ciais, P., 2009. Is there an optimal timing for sequestration to stabilize future climate? American Geophysical Union, Geophysical Monograph, Washington, DC.

[11] Gradus, Smulders, S., 1996. Pollution Abatement and Long-term Growth. European Journal of Political Economy 12, 505-532. 
[12] Grimaud, A., Magne, B., Rouge, L., 2009. Carbon Storage and Climate Policy in a Growth Model with Innovation. IDEI Working Paper.

[13] Hartwick, R., 1977. Intergenerational Equity and the Investing of Rents from Exhaustible Resources. American Economic Review 67, 972-974.

[14] Heal G. M., 1993. The Optimal Use Of Exhaustible Resources, in Handbook of Natural Resource and Energy Economics, vol. III, A.V. Kneese and J.L. Sweeney (Eds), Elsevier Science Publishers.

[15] Hotteling, H., 1931. The Economics of Exhaustible Resources. The Journal of Political Economy 39, 137-175.

[16] IPCC, 2005. Special Report on Carbon Dioxide Capture and Storage, Contribution of Working Group III, Report of the Intergovernmental Panel on Climate Change. Cambridge Univ. Press, Cambridge.

[17] Kurosawa, A., 2004. Carbon concentration target and technological choice. Energy Economics 26, 675-684.

[18] Lafforgue, G., Magne B., Moreaux M., 2008. Energy substitutions, climate change and carbon sinks. Ecological Economics 67, 589-597.

[19] Lafforgue, G., Magne B., Moreaux M., 2008. The optimal sequestration policy with a ceiling on the stock of carbon in the atmosphere. In The Design of Climate Policy (Chapter 14, pp. 273-304), R. Guesnerie and H. Tulkens eds, Boston: The MIT Press.

[20] McFarland, J.R., Herzog, H.J., Reilly, J.M., 2003. Economic modelling of the global adoption of carbon capture and sequestration technologies. In: Gale, J., Kaya, Y. (Eds.), Proceedings of the Sixth International Conference on Greenhouse Gas Control Technologies. Elsevier Science, Oxford.

[21] Ragot, L., Schubert K., 2009. The optimal carbon sequestration in agricultural soils: do the dynamics of the physical process matter?. Journal of Economic Dynamics and Control, in press.

[22] van der Ploeg and Withagen C., 1991., Pollution Control and the Ramsey Problem. Environmental and Resource Economics 1, 215-236. 